\title{
STATUS DAN STRATEGI PENGELOLAAN LINGKUNGAN PERHOTELAN DI KAWASAN KOTA MADYA DILI TIMOR - LESTE
}

\author{
Adalgisa D.D.G. Alvares ${ }^{1 *}$, Budiarsa Suyasa ${ }^{2)}$, Syamsul A. Paturusi ${ }^{3)}$ \\ 1)Kementerian Pertanian dan Perikanan Timor-Leste \\ ${ }^{2)}$ Program Doktor Ilmu Lingkungan Universitas Udayana \\ ${ }^{3)}$ Program Magister Kajian Pariwisata Universitas Udayana \\ *E-mail: zizaguterres@yahoo.com
}

\begin{abstract}
The research held about to reach two goals. To find out the condition and the strategy about the management of hotel environment at Dili. The decision of area research is held with purposive. All hotel in Dili will be chosen as the samples, it means that it will be held with census. Next, as the respondents in this research is the manager of the hotels. The result of this research shows that there are seven variables. They are the loyalty for its regulation, the programme and appreciation of environment, green park and space, the management of waste water, the management of rubbish, the management of emission, the management of non enviromental things. The indicator of the regulation (rules) of the company can be identified by using AMDAL document. The indicator of the programme and appreciation of environment can be identified by using the policy and appreciation that is dotained from this environment. The indicator of waste water management, can be recognized by using IPAL. The indicator of rubbish management can be recognized by using its mechanism. The indicator of emission management can be recognized by using its mechanism. The indicator of non environmental things management can be identified by using its mechanism. The level of this implementation for the hotel environment at Dili is about $65,08 \%$ (Fairly). The implementation of per variable can be seen that the percentage of the loyalty for its regulation is about $74,8 \%$ (good), the programme and appreciation of environment is about $44 \%$ (not good), green park and space is about 76,8\% (good), the management of waste water is about $81,6 \%$ (good), the management of rubbish is about $60,8 \%$ (fairly), the management of emission is about $63,2 \%$ (fairly), the non enviromental things management is about $54,4 \%$ (fairly). The indicator supported by the environment needs the attention of hotel management which improves the hotel image for tourist or guests in the hotel.
\end{abstract}

Key Words : Hotel, Area, Dili, Management, Condition, Strategy

\section{PENDAHULUAN}

Saat ini masalah lingkungan telah menjadi isu global, ditengah-tengah proses pembangunan yang berjalan pesat. Lingkungan alam, sangat penting bagi manusia yang menjadi subyek pembangunan. Protes,friksi, dan konflik yang kini terjadi dalam proses pembangunan, karena manusia merasa telah terdesak secara sosial,ekonomi, dan juga lingkungan. Dampak lingkungan, bisa menyebabkan kehidupan manusia menjadi tidak sehat,terdesak, dan tidak mendapatkan manfaat yang wajar dari proses pembangunan dikawasannya.

Pembangunan hotel dan infrastruktur lainnya di Kota Dili telah menekankan pada keberlanjutan prospek di bidang pariwisata. Hal ini tercermin pada visi pembangunan kota Dili tahun 2011-2030 yakni : menuju pembangunan berkelanjutan. Esensinya adalah bahwa pembangunan Kota Dili memang diharapkan akan menuju pada kemakmuran dan kesejahteraan masyarakat. Namun dalam proses untuk tujuan itu, haruslah dilandaskan pada prinsip harmoni dan kebersamaan, sesuai dengan hakekat konsep pembangunan nasional. Seiring dengan penerapan strategi pembangunan pada Kawasan di Kota Dili, maka hotel yang kini banyak dibangun di Dili, diharapkan juga menerapkan strategi pengelolaan lingkungan yang baik karena pembangunan hotel dalam proses pembangunan kepariwisataan di Kota Dili memiliki dampak yang sangat besar.

Oleh karenanya, perlu ada penelitian tentang status dan strategi pengelolaan lingkungan perhotelan pada hotel-hotel di Kota Dili Timor-Leste, Adapun tujuan pokok dari penelitian ini adalah sebagai berikut : mengetahui status pengelolaan lingkungan perhotelan di Kawasan Kota Dili dan menyusun strategi pengelolaan lingkungan perhotelan di Kawasan Kota Dili.

\section{METODOLOGI}

Penelitian ini dilakukan di Kota Madya Dili Timor-Leste. Penelitian ini merupakan penelitian survei yang menggunakan pendekatan secara deskriptif kualitatif yang dikombinasikan dengan 
analisis SWOT. Teknik pengumpulan data dilakukan dengan cara observasi lapangan, wawancara (interview) dan dokumentasi. Metode dan teknik analisis data yang digunakan adalah analisis deskriptif kualitatif dan analisis SWOT (Rangkuti, 2014).

\section{HASIL DAN PEMBAHASAN}

\subsection{Gambaran Umum Lokasi Penelitian}

Kota Dili merupakan Pusat Ibu Kota Negara Timor-Leste segala aktivitas terpusat di Kota Dili salah satu sektor yang bergerak maju adalah sektor pariwisata dimana Kota Dili mempunyai beberapa Ikon pariwisata yang sangat menarik para wisatawan untuk berkunjung ke Kota Dili.

Berdasarkan data dari Badan Pertanahan Nasional Timor-Leste tahun (2009), luas wilayah secara keseluruhan Kota Dili adalah 13.637,97 hektar yang terbagi dalam 6 Kecamatan yaitu Kecamatan Dom Aleixo, Kecamatan Cristo Rei, Kecamatan Vera Cruz, Kecamatan Nain Feto, Kecamatan Metinaro, Kecamatan Atauro.

Melihat kondisi riil di lapangan bahwa semua hotel yang menjadi sampel dalam penelitian ini terletak pada empat Kecamatan di Kota Dili TimorLeste yaitu pada Kecamatan Cristo Rei, Kecamatan Dom Aleixo, Kecamatan Vera Cruz dan Kecamatan Nain Feto

\subsection{Status Pengelolaan Lingkungan Perho- telan di Kawasan Kota Dili}

Dalam kaitannya dengan penelitian tentang status pengelolaan lingkungan perhotelan harus dilaksanakan dengan tidak hanya untuk memahami lingkungan fisik saja tetapi perlu juga memahami berbagai hal yang berkaitan dengan lingkungan manusia dan lingkungan spiritual. Hal itu disebabkan karena hotel menampung para tamu yang memiliki karakter yang berbeda-beda, namun mereka memerlukan ketenangan dan harmoni dalam kehidupannya. Dengan adanya harmoni, maka keberlanjutan eksistensi hotel di kawasan itu akan lebih terjamin dan para tamu yang menginap di hotel tersebut merasa nyaman dan puas tinggal di hotel tersebut.Semua data yang ditampilkan dalam Tabel 1 tersebut bersumber dari data yang dikumpulkan di lapangan dan selanjutnya di tampilkan dalam Tabel 1.

Tabel 1. menunjukkan bahwa penerapan status dalam pengelolaan lingkungan perhotelan di Kawasan Kota Dili termasuk kategori cukup dengan skor $65,08 \%$. Hal ini mungkin disebabkan karena minimnya sumberdaya manusia di bidang perhotelan dalam mengelola managemen perhotelan dan kurangnya campur tangan pemerintah dalam memonitoring aktivitas perhotelan di Kota Dili, dengan demikian kesadaran tentang peranan lingkungan yang sangat penting artinya dalam perkembangan pariwisata perlu diperhatikan dengan

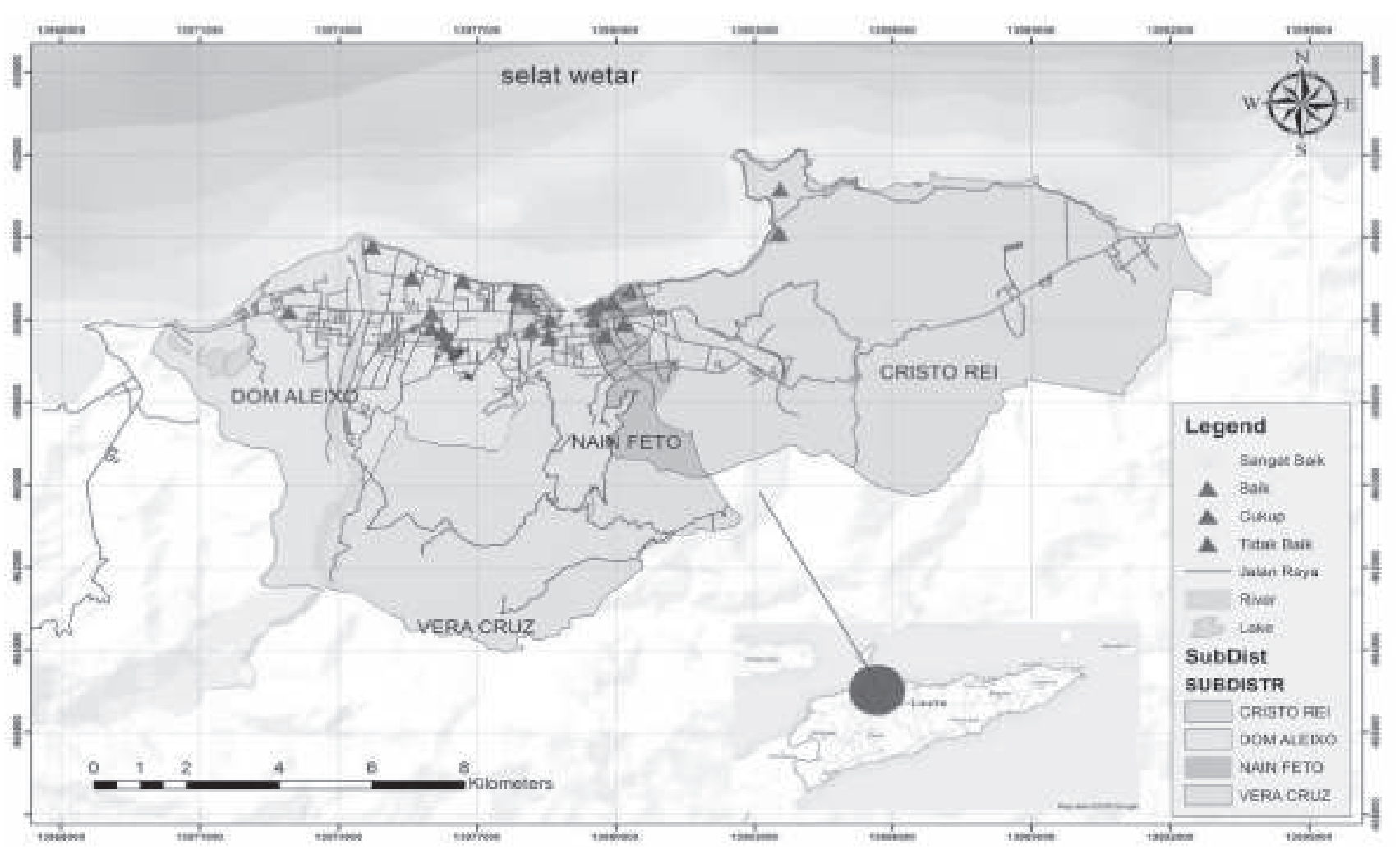

Gambar 3.1. Peta Lokasi Penelitian

Sumber : Dili Urban Master Plan, 2015. 
Tabel 1. Nilai Skor Rata-rata Status Pengelolaan Lingkungan Perhotelan

\begin{tabular}{|c|c|c|c|c|}
\hline \multirow{3}{*}{$\frac{\text { No }}{1}$} & \multirow{2}{*}{$\begin{array}{l}\text { Variabel } \\
\text { Ketaatan pada Peraturan }\end{array}$} & \multicolumn{2}{|c|}{ Indikator } & \multirow{2}{*}{$\frac{\text { Nilai Skor (\%) }}{100}$} \\
\hline & & 1.1 & Adanya Izin Usaha & \\
\hline & & 1.2 & Adanya Dokumen AMDAL & 49,6 \\
\hline & Jumlah & & & 149,6 \\
\hline & Rata-rata & & & 74,8 \\
\hline \multirow[t]{4}{*}{2} & Program dan Penghargaan & 2.1 & Kebijakan Lingkungan & 57,6 \\
\hline & & 2.2 & Penghargaan Lingkungan & 30,4 \\
\hline & Jumlah & & & 88 \\
\hline & Rata-rata & & & 44 \\
\hline \multirow[t]{4}{*}{3} & Taman dan RTH & 3.1 & Taman di kawasan Hotel & 69,6 \\
\hline & & 3.2 & Ruang Terbuka Hijau & 84 \\
\hline & Jumlah & & & 153,6 \\
\hline & Rata-rata & & & 76,8 \\
\hline \multirow[t]{3}{*}{4} & Pengelolaan Air Limbah & 4.1 & Mekanisme IPAL & 81,6 \\
\hline & Jumlah & & & 81,6 \\
\hline & Rata-rata & & & 81,6 \\
\hline \multirow[t]{3}{*}{5} & Pengelolaan Sampah & 5.1 & Mekanisme Pengelolaan Sampah & 60,8 \\
\hline & Jumlah & & & 60,8 \\
\hline & Rata-rata & & & 60,8 \\
\hline \multirow[t]{3}{*}{6} & Pengelolaan Emisi & 6.1 & Mekanisme Pengelolaan Emisi & 63,2 \\
\hline & Jumlah & & & 63,2 \\
\hline & Rata-rata & & & 63,2 \\
\hline \multirow[t]{4}{*}{7} & Pengelolaan B3 & 7.1 & Mekanisme Pengelolaan B3 & 54,4 \\
\hline & Jumlah & & & 54,4 \\
\hline & Rata-rata & & & 54,4 \\
\hline & Skor Rata-rata & & & 65,08 \\
\hline
\end{tabular}

Sumber: Data Hasil Penelitian Hotel di Kota Dili, 2016.

baik. Oleh karena itu pihak hotel tentu saja harus mengantisipasi permasalahan itu, dengan secara sungguh-sungguh memperhatikan masalah lingkungannya.

Berkaitan dengan eksistensi variabel tentang status pengelolaan lingkungan perhotelan di kawasan Kota Dili, maka berikut akan diuraikan penerapan ketujuh elemen dalam status pengelolaan lingkungan perhotelan sebagai berikut:

\subsubsection{Status Pengelolaan Lingkungan Variabel Perizinan}

Indikator pengelolaan lingkungan diukur dengan berbagai parameter dalam penelitian ini parameter yang digunakan untuk mengukur adalah: Adanya Izin Usaha, dalam penelitian ini didapatkan skor adalah $100 \%$ (Sangat Baik). Hal ini menunjukkan bahwa dalam menerapkan variabel ketaatan pada perizinan/peraturan yang ada semua pihak hotel sudah memiliki kesadaran yang tinggi dalam hal ini semua pihak hotel telah memiliki izin usaha. Adanya dokumen AMDAL/UKL/UPL, ada pelaporan pelaksanaan sesuai aturan yang berlaku, ada pelatihan pada staf, ada program lingkungan, ada pengelolaan lingkungan bersama masyarakat. Adapun skor yang didapat adalah 49,6\% (tidak baik ). Hal ini menunjukkan bahwa kesadaran pihak hotel terhadap sistem dokumen pengelolaan lingkungan sangat minim.

\subsubsection{Status Pengelolaan Lingkungan Variabel Program dan Penghargaan Lingkungan}

Berbagai indikator yang diukur dalam elemen program dan penghargaan lingkungan adalah: (i) Kebijakaan lingkungan; (ii) Penghargaan lingkungan. Dalam penelitian ini didapatkan skor adalah 57,6\% (Cukup/Sedang). Hal ini menunjukkan bahwa dalam kegiatan operasional hotel pihak hotel belum menerapkan kebijakan lingkungan secara merata di lingkungan perhotelan.

Salah satu indikator yang diukur dalam penelitian ini adalah variabel penghargaan lingkungan dalam penelitian ini didapatkan skor adalah 30,4 \% (sangat tidak baik). Hal ini menunjukkan bahwa dalam kegiatan operasional hotel, pihak hotel belum secara serius memperhatikan berbagai aspek lingkungan.

\subsubsection{Status Pengelolaan Lingkungan Variabel Taman dan RTH}

Berbagai indikator yang diukur dalam variabel taman dan RTH adalah (i) Taman di kawasan hotel, (ii) Ruang terbuka hijau (RTH). Bahwa skor ratarata untuk variabel Taman dan RTH adalah sebesar 
$76,8 \%$ (baik). Skor tertinggi dicapai oleh indikator ruang terbuka hijau (RTH) dengan skor $84 \%$ (sangat baik). Skor 69,6\% (baik) dicapai oleh indikator taman dikawasan hotel. Dengan melihat data tersebut dapat dikatakan logis kalau pihak hotel mengutamakan penataaan taman di kawasan hotel sebagai hal yang penting dan diutamakan karena menyangkut citra hotel kepada tamu-tamunya secara langsung di kawasan hotel tersebut.

\subsubsection{Status Pengelolaan Lingkungan Variabel Pengelolaan Air Limbah}

Berbagai indikator yang diukur dalam variabel pengelolaan air limbah adalah mekanisme Instalasi Pengolahan Air Limbah (IPAL) tercatat bahwa skor 81,6\% (baik). Hal ini menunjukkan bahwa perhatian pihak hotel dalam pengelolaan limbah sudah baik.

\subsubsection{Status Pengelolaan Lingkungan Variabel Pengelolaan Sampah}

Berbagai indikator yang diukur dalam variabel pengelolaan sampah adalah mekanisme pengolahan sampah tercatat bahwa skor 60,8 \% (cukup/ sedang). Hal ini menunjukkan bahwa perhatian pihak hotel dalam melakukan proses pengolahan sampah di kawasan hotel masih sangat minim.

\subsubsection{Status Pengelolaan Lingkungan Variabel Pengelolaan Emisi}

Indikator yang diukur dalam variabel pengelolaan emisi adalah mekanisme pengelolaan emisi tercatat bahwa skor 63,2\% (cukup/sedang). Hal ini menandakan bahwa perhatian pihak hotel dalam pengelolaan emisi perlu terus ditingkatkan. Pada hal masalah pengelolaan emisi adalah masalah yang sangat penting agar lingkungan alam tetap lestari dan eksistensi hotel akan tetap berlanjut.

\subsubsection{Pengelolaan Lingkungan Variabel Pengelolaan B3}

Indikator yang diukur dalam variabel Pengelolaan B3 adalah mekanisme pengelolaan B3 tercatat bahwa skor 54,4\% (cukup / sedang). Hal ini menunjukkan bahwa perhatian pihak hotel dalam pengelolaan B3 perlu diawasi oleh pihak pemerintah. Jadi perlu perhatian serius dari pihak pemerintah dalam memonitoring segala aktivitas operasional hotel di Kawasan Kota Dili.

Tabel 2. Implementasi Status Pengelolaan Lingkungan pada Masing-masing Hotel.

\begin{tabular}{|c|c|c|c|c|c|c|c|c|c|c|}
\hline \multirow{2}{*}{ No. } & \multirow{2}{*}{ Nama Hotel } & \multicolumn{7}{|c|}{ Rata - rata Implementasi ( \% ) } & \multirow{2}{*}{$\begin{array}{c}\text { Implementasi } \\
(\%)\end{array}$} & \multirow{2}{*}{$\begin{array}{l}\text { Rata-rata } \\
\text { Keterangan }\end{array}$} \\
\hline & & Perizinan & Program & $\begin{array}{l}\text { Taman } \\
\text { \& RTH }\end{array}$ & Limbah & Sampah & Emisi & B3 & & \\
\hline
\end{tabular}

\begin{tabular}{|c|c|c|c|c|c|c|c|c|c|c|}
\hline 1. & Hotel Timor & 100 & 100 & 100 & 100 & 40 & 100 & 100 & 91,4 & Sangat Baik \\
\hline 2. & Novo Turismo & 60 & 20 & 100 & 80 & 80 & 100 & 60 & 81,2 & Baik \\
\hline 3. & Timor Plaza & 90 & 20 & 30 & 60 & 80 & 100 & 60 & 85,7 & Sangat Baik \\
\hline 4. & Ramelau & 100 & 70 & 70 & 60 & 40 & 80 & 60 & 68,5 & Baik \\
\hline 5. & Terra Santa & 60 & 20 & 100 & 80 & 40 & 100 & 80 & 68,5 & Baik \\
\hline 6. & Excel Beach & 100 & 60 & 100 & 80 & 80 & 100 & 100 & 88,7 & Sangat baik \\
\hline 7. & JL Villa & 60 & 20 & 80 & 80 & 40 & 20 & 20 & 45,7 & Tidak baik \\
\hline 8. & D'City & 80 & 20 & 70 & 80 & 20 & 80 & 60 & 58,5 & Cukup \\
\hline 9. & Dili Beach & 80 & 90 & 80 & 80 & 40 & 20 & 20 & 58,5 & Cukup \\
\hline 10. & Lecidere & 60 & 60 & 60 & 80 & 100 & 60 & 20 & 62,8 & Cukup \\
\hline 11. & Discovery Inn & 100 & 60 & 70 & 100 & 100 & 100 & 20 & 78,5 & Baik \\
\hline 12. & The Plaza & 60 & 60 & 80 & 100 & 80 & 60 & 60 & 71,4 & Baik \\
\hline 13. & Diamond & 60 & 20 & 100 & 80 & 40 & 20 & 20 & 48,5 & Tidak baik \\
\hline 14. & Santos Living & 90 & 60 & 100 & 100 & 40 & 20 & 60 & 67,1 & Cukup \\
\hline 15. & Sakura & 60 & 20 & 40 & 80 & 40 & 100 & 20 & 51,4 & Tidak baik \\
\hline 16. & Oceanview & 60 & 20 & 80 & 80 & 40 & 60 & 20 & 51,4 & Tidak baik \\
\hline 17. & Kolmera & 60 & 20 & 90 & 80 & 40 & 20 & 20 & 47,1 & Tidak baik \\
\hline 18. & Ventura & 70 & 20 & 80 & 80 & 80 & 20 & 80 & 64,2 & Cukup \\
\hline 19. & Beachside & 100 & 70 & 60 & 80 & 100 & 60 & 100 & 81,4 & Baik \\
\hline 20. & Novo Horizonte & 60 & 70 & 60 & 80 & 80 & 60 & 60 & 67,1 & Cukup \\
\hline 21. & Farol & 100 & 60 & 100 & 80 & 20 & 100 & 100 & 80 & Baik \\
\hline 22. & VilaVerde & 80 & 80 & 30 & 80 & 100 & 20 & 20 & 58,5 & Cukup \\
\hline 23. & Fen Kong & 60 & 20 & 80 & 80 & 40 & 20 & 20 & 45,7 & Tidak baik \\
\hline 24. & Roccela & 60 & 20 & 100 & 80 & 100 & 100 & 100 & 80,8 & Baik \\
\hline 25. & Sorte Diak & 60 & 20 & 60 & 80 & 60 & 60 & 80 & 60 & Cukup \\
\hline
\end{tabular}


3.3 Kriteria dan Implementasi Status Pengelolaan Lingkungan pada Masingmasing Hotel

Kriteria implementasi status pengelolaan lingkungan perhotelan pada masing-masing hotel di kawasan Kota Dili perlu diketahui. Hal itu penting, agar diperoleh gambaran tentang bagaimana pihak hotel mampu mengimplementasikan status pengelolaan lingkungan perhotelan.

Data pada tabel 2 menunjukkan bahwa dari 25 hotel yang diteliti, enam hotel yang mengimplementasikan status pengelolaan lingkungan pada masing-masing hotel dalam kategori Tidak Baik, delapan hotel berkategori Cukup, delapan hotel berkategori Baik dan tiga hotel berkategori Sangat Baik. Secara umum Implementasi status pengelolaan lingkungan hotel di Kawasan Kota Dili adalah cukup.

Hotel di kawasan kota Dili, yang skor implementasinya paling tinggi adalah Hotel Timor ( 91,4 \% ) dengan kategori sangat baik. Sedangkan hotel yang implementasinya paling rendah adalah
Hotel JL Villa dan Hotel Fen Kong (45,7 \%) dengan kategori tidak baik, umumnya skor yang implementasinya paling rendah adalah penerapan variabel program dan penghargaan lingkungan.

\subsection{Deskripsi dan Implementasi Status Pengelolaan Lingkungan Perhotelan di Kawasan Kota Dili}

Berdasarkan hasil observasi dan melalui kegiatan wawancara mendalam baik secara individu maupun melalui diskusi dengan pihak managemen hotel diperoleh gambaran bahwa, hotel-hotel di Kawasan Kota Dili harus fokus untuk memperhatikan implementasi aktivitas operasional hotel yang berhubungan dengan kondisi pengelolaan lingkungan dengan lebih optimal untuk memperbaiki kinerja hotel ke masa depan yang lebih baik, agar wisatawan atau tamu lebih senang untuk mengunjungi Kawasan pariwisata di Kota Dili, hal ini perlu di perhatikan oleh pihak manajemen hotel dan pemerintah setempat.

\subsection{Analisis SWOT Strategi Pengelolaan Lingkungan Perhotelan di Kawasan Kota Dili}

\section{Faktor Internal}

Faktor Eksternal Peluang

1. Terciptanya kawasan perhotelan yang nyaman dan bersih.

2. Terjaganya kelestarian sumberdaya lingkungan sekitarnya.

3. Adanya peningkatan minat wisatawan domestik dan mancanegara

\section{Ancaman}

1. Adanya ancaman atau sanksi dari pemerintah

2. Adanya komplain dari masyarakat

3. Kerusakan lingkungan

4. Turunnya minat wisatawan

\section{Kekuatan}

1. Sebagian besar hotel telah memiliki ketaatan pada perizinan lingkungan yang lengkap

2. Beberapa hotel telah memiliki program dan kebijakaan lingkungan yang baik tercermin pada hotel Timor,Ramelau,Timor Plaza, Novo Turismo

3. Beberapa hotel memiliki Taman dan RTH seluas $40 \%$ dari luas hotel tercermin pada hotel Timor, Ramelau,Novo Turismo, Terra Santa,JL Villa, Santos Living

4. Beberapa hotel telah memiliki sistem pengelolaan sampah yang representatif tercermin dari kebersihan lingkungan di hotel tercermin pada hotel Timor, Ramelau,Novo Turismo, Timor Plaza

5. Beberapa hotel telah memiliki sistem pengelolaan limbah, emisi dan B3 yang baik tercermin pada hotel Timor,Ramelau,Timor Plaza, Novo Turismo

\section{Strategi SO}

1. Peningkatan penerapan sistem pengelolaan limbah, sampah secara berkelanjutan dengan menerapakan 3R.

2. Meningkatkan sistem pelaporan pengelolaan lingkungan kepada pemerintah.

3. Menyediakan mekanisme insentif bagi hotel yang menerapkan sistem pengelolaan lingkungan yang sesuai dengan standar yang ditetapkan.

\section{Strategi ST}

1. Meningkatkan program pengelolaan lingkungan secara berkelanjutan

2. Mendorong hotel untuk tetap menjaga lingkungan dan komunikasi yang baik dengan masyarakat di sekitarnya secara berkelanjutan.

3. Melakukan inovasi secara terus menerus dalam penataan lingkungan perhotelan untuk meningkatkan kenyamanan tamu/wisatawan.

\section{Kelemahan}

1. Masih ada hotel yang belum memiliki kebijakaan lingkungan tercermin pada hotel JL Villa, Diamond, Sakura, Oceanview, kolmera, Fen Kong.

2. Masih ada beberapa hotel yang tidak memiliki Taman yang memadai (luasnya $<10 \%$ dari luas area)

3. Masih ada hotel yang belum menerapkan sistem pengelolaan sampah yang memadai.

4. Mekanisme pengelolaan limbah,emisi dan B3 pada beberapa hotel belum memenuhi kriteria

\section{Strategi WO}

1. Sosialisasi ketaatan terhadap implementasi perizinan dan dokumen lingkungan pada pihak hotel

2. Penerapan mekanisme sanksi kepada hotel yang tidak menerapkan sistem pengelolaan limbah, sampah sesuai dengan standar yang ditetapkan.

3. Mengadakan kegiatan lomba pada sistem pengelolaan lingkungan hotel secara periodik.

\section{Strategi WT}

1. Mendorong hotel untuk memenuhi segala bentuk perizinan dan dokumen lingkungan yang di perlukan

2. Mendorong hotel untuk menjaga lingkungan dan komunikasi yang baik dengan masyarakat di sekitarnya

3. Melakukan penataan lingkungan perhotelan untuk meningkatkan kenyamanan tamu/wisatawan.

Sumber : Data Hasil Penelitian, 2016. 


\section{SIMPULAN DAN SARAN}

\subsection{Simpulan}

Berdasarkan uraian pada hasil dan pembahasan penelitian, dan juga dengan mengacu pada tujuan penelitian, maka dapat disimpulkan sebagai berikut: 1. Status Pengelolaan lingkungan perhotelan di kawasan kota Dili terlihat bahwa hotel di Kawasan Kota Dili dengan skor penerapan status pengelolaan lingkungan tertinggi adalah Hotel Timor dengan skor (91,4\%), Hotel Timor Plaza dengan skor (85,7\%) dan Hotel Excel Beach dengan skor (88,7 \%) dengan kriteria Sangat Baik. Hotel dengan penerapan status pengelolaan lingkungan dengan Kategori Baik adalah Hotel Novo Turismo dengan skor (81,2 $\%)$, Hotel Beachside dengan skor (81,4\%), Hotel Rocella dengan skor (80,8 \%), Hotel Farol dengan skor (80 \%), Hotel Discovery Inn dengan skor (78,5 \%), Hotel the Plaza dengan skor (71,4\%), Hotel Ramelau dengan skor (68,5\%) dan Terra Santa dengan skor (68,5\%). Hotel dengan penerapan status pengelolaan lingkungan dengan Kategori Cukup adalah Santos Living dengan skor (67,1\%), Hotel Novo Horizonte $(67,1$ $\%)$, Hotel Ventura dengan skor (64,2\%), Hotel D'City dengan skor (58,5\%), Hotel Dili Beach dengan skor (58,5\%) dan Hotel Vila Verde (58,5 $\%)$. Hotel dengan penerapan status pengelolaan lingkungan dengan Kategori Tidak Baik adalah Oceanview Hotel dengan skor (51,4\%), Hotel Sakura dengan skor (51,4 \%), Diamond Villa dengan skor (48,5\%), Hotel Kolmera dengan skor (47,1\%), JL Villa (45,7\%) dan Fen Kong (45,7\%). Tingkat Implementasi Status Pengelolaan lingkungan perhotelan di Kawasan Kota Dili adalah sebesar 65,08\% dengan kategori Cukup.

2. Untuk mendorong hotel menerapkan pengelolaan lingkungan maka diperlukan strategi sebagai berikut:

a. Sosialisasi ketaatan terhadap implementasi perizinan dan dokumen lingkungan pada pihak hotel.

b. Penerapan mekanisme sanksi kepada hotel yang tidak menerapkan sistem pengelolaan limbah, sampah sesuai dengan standar yang ditetapkan.

Mengadakan kegiatan lomba pada sistem pengelolaan lingkungan hotel secara periodik.

\subsection{Saran}

1. Hotel yang penerapan status pengelolaan lingkungan, dengan kriteria belum baik, perlu melakukan berbagai kegiatan yang berkaitan dengan implementasi status pengelolaan lingkungan, agar kategorinya dapat meningkat. Kegiatan yang dilakukan, sesuai dengan berbagai indikator pada variabel program dan penghargaan lingkungan tersebut.

2. Penerapan status pengelolaan lingkungan dalam kategori skor tidak baik dan cukup, masih ditemukan pada elemen program dan penghargaan lingkungan, pengelolaan sampah, pengelolaan emisi pada beberapa hotel. Untuk itu perlu terus dikembangkan agar semua variabel pengelolaan lingkungan pada hotel-hotel di kawasan kota Dili, dapat masuk dalam kategori minimal Baik.

3. Indikator hotel yang berbasis lingkungan kiranya dapat terus dikembangkan lebih lanjut, dan terus diuji pada kawasan pariwisata yang lebih luas, sehingga dengan demikian akan didapatkan suatu indikator yang baku di masa yang akan datang. Dengan demikian akan dapat dijadikan sebagai pegangan pokok dalam menilai status dan strategi pengelolaan lingkungan pada hotel-hotel di kawasan kota Dili

4. Penelitian ini merupakan penelitian yang baru jadi perlu diteruskan atau dilanjutkan dalam penelitian berikutnya karena penelitian ini merupakan sumber informasi bagi pihak pemerintah dan hotel untuk diketahui sejauh mana kondisi dan strategi pengelolaan lingkungan perhotelan pada saat ini.

\section{DAFTAR PUSTAKA}

Adi, Ni Putu Massuli. 2015. "Pengelolaan Lingkungan Hotel Berbasis Tri Hita Karana di Kawasan Pariwisata Sanur." (Tesis). Denpasar: Universitas Udayana.

Kementerian Pariwisata Timor Leste, 2014. Data Jumlah Hotel yang Beroperasi di Kota Dili.

Groiler Electronis Publising. Inc.1995. Pengertian Hotel dan Defenisi Hotel.

Lensiana.HJ. 2010. "Partisipasi Hotel Dalam Pengelolaan Lingkungan di Kelurahan Ubud, Kabupaten Gianyar.”(Tesis). Denpasar: Universitas Udayana.

Rangkuti, Freddy. 2013. Analisis SWOT : Teknik Membedah Kasus Bisnis. Jakarta: PT. Gramedia Pustaka Utama.

Stedmon \& Kasavana.2004. Resepsionis Hotel. Jakarta. Penerbit Gramedia Pustaka Utama.

Undang- Undang Lingkungan Hidup Timor - Leste No. 26 Tahun 2012. Tentang Pengelolaan Lingkungan hidup.

Undang-Undang No. 26 Tahun 2007. Tentang Penataan Ruang.

Undang-undang No. 32 Tahun 2009. Tentang Pengelolaan Lingkungan Hidup. 